\title{
Taflan (Prunus laurocerasus L) Yaprağı ve Çekirdeğinin Ferrotiyosiyanat Metoduyla Total Antioksidan Kapasitesinin Belirlenmesi
}

\author{
Ayşegül ÇEBİ \\ Giresun Üniversitesi, Mühendislik Fakültesi, Gıda Mühendisliği Bölümü, 28100, Giresun, Türkiye
}

Sorumlu Yazar: aysegul.cebi@giresun.edu.tr

Geliş Tarihi: 15.11 .2017

Kabul Tarihi: 07.06.2018

\begin{abstract}
Özet
Taflan veya karayemiş olarak da bilinen Prunus laurocerasus Karadeniz bölgesinde yaygın olarak bulunmaktadır. Ordu ilinden 2016 Ağustos ayında yaprakları ve meyveleri toplanan P. laurocerasus bitkisinin toplam antioksidan kapasitesini belirlemek amacıyla bu çalışma yapılmıştır. Toplanan örnekler yaprak ve meyvenin çekirdeği olmak üzere ayrılmış, metanol ve etanol çözücüleri içerisinde çözülerek ayrı ekstraktlar elde edilmiştir. Toplam antioksidan kapasitesi ferrotiyosiyanat metoduna göre hazırlanan ekstraktlarda 12 saatte bir olmak üzere spektrofotometrik olarak ölçülmüştür. En yüksek inhibisyon yüzdesi metanol ekstraktları için 84. saatte gerçekleşmiştir. P. laurocerasus metanol ekstraktının yaprağı için yüzde inhibisyon değeri 66,97, çekirdeği için 67,10 olarak belirlenmiştir. Yaprak ve çekirdeklerinin etanol ekstraktları ise 48. saatte en yüksek yüzde inhibisyon göstererek 94,67 ve 91,06 değerlerine ulaşmışlardır. Butilen hidroksi toluene (BHT) ve troloksun yüzde inhibisyon değerleri 48. Saatte 39,85 ve 43,81 olarak hesaplanmıştır. P. laurocerasus yaprağı ve çekirdeğinin standart antioksidanlara göre yüksek antioksidan aktivite gösterdiği tespit edilmiştir. Ayrıca etanol ekstraktının da metanol ekstraktına göre daha yüksek antioksidan aktivite verdiği görülmüştür. $P$. laurocerasus çekirdeğinin ise yaprağına göre daha yüksek antioksidan kapasiteye sahip olduğu söylenebilir.
\end{abstract}

Anahtar Kelimeler: Prunus laurpcerasus, antioksidan, ferrotiyosiyanat, etanol.

\section{Determination of Total Antioxidant Capacities by Ferrous Thiocyanate Method in Leaf And Seed of Cherry Laurel (Prunus laurocerasus L)}

\begin{abstract}
Prunus laurocerasus, also known as taflan or karayemiş, is commonly found in the Black Sea region. This study was carried out to determine total antioxidant capacity of $P$. laurocerasus plant collected leaves and fruits from Ordu province in August 2016. The collected samples were separated into leaves and fruit kernel, and dissolved in methanol and ethanol solvents to obtain separate extracts. The total antioxidant capacity was measured spectrophotometrically at $12 \mathrm{~h}$ in extracts prepared according to the ferrous thiocyanate method. The highest percent inhibition occurred at 84 hours for methanol extracts. The percent inhibition value for the methanol extract of P. Laurocerasus was determined to be 66.97 and 67.10 for the leave and kernel, respectively. The ethanol extracts of leaves and seeds showed the highest percent inhibition at 48th hour, reaching 94.67 and 91.06. Percent inhibition values of the butylated hydroxy toluen (BHT) and trolox were calculated as 39.85 and 43.81 in 48th hour. It was determined that the leaf and kernel of P. laurocerasus showed high antioxidant activity compared to standard antioxidants. It was also found that the ethanol extract gave higher antioxidant activity than the methanol extract. The kernel of the P. Laurocerasus has higher antioxidant capacity than the leaf.
\end{abstract}

Keywords: Prunus laurocerasus, antioxidant, ferrous thiocyanate, ethanol. 


\section{Giriş}

Taflan olarak bilinen P. laurocerasus Güneybatı Asya, Güneydoğu Avrupa ve Karadeniz kıyılarında doğal olarak bulunmaktadır. Rosaceae familyası ve Prunoideae subfamilyasına ait olan $P$. laurocerasus bitkisine özellikle Doğu Karadeniz bölgesinde sıklıkla rastlanmakta ve yemişleri besin olarak tüketilmektedir. Halk arasında analjezik, antispasmodik ve sedatif etkilerinin yanında kan şekerini düşürücü etkisinin olduğu da bilinmektedir (Kolaylı ve ark., 2003). Herhangi bir mide lezyonuna yol açmadan anti-enflamatuar bir etkisinin olduğu kaydedilmiştir (Erdemoglu ve ark., 2003). Taflan bitkisinin meyve ve çekirdeği sindirim ve solunum hastalıkları, bronşit, egzema ve hemoroid tedavisinde tavsiye edilmiştir (Çolak ve ark., 2005, Kolaylı ve ark., 2003).

Taflan bitkisinin meyvesinin sahip olduğu fenolik içerik sayesinde besinsel ve farmasötik değeri çoktur. Meyvesindeki en sık rastlanan fenolik içerikler benzoik asit, klorojenik asit, vanillik asit ve kafeik asit iken, antosiyanin, bazı mineral maddeler, vitamin $\mathrm{C}$ ve tannin ise yapısında bulunan diğer maddelerdendir (Alaşalvar ve ark., 2005, Çolak ve ark., 2005, Kolaylı ve ark., 2003, Ayaz, 2001). Taflan bitkisi sahip olduğu fenolik içerikler sayesinde antioksidan aktiviteye sahiptir. Antioksidanlar pekçok hastalık sürecinde ortaya çıkan okside substratın oksidasyonunu engeller veya geciktirir (Gülçin ve ark., 2005). Bitkinin bünyesinde ortaya çıkan bu sekonder metabolitler bitkiyi dış etkenlerden korumak için gereklidir. Hidroksil radikali ve süperoksit radikali gibi serbest radikalleri süpürücü etki, tek elektron transferi, hidrojen aktarma ve metal iyon şelatlama mekanizmalarıyla fenolik maddeler antioksidan etki gösterebilirler (Liyana-Pathirana ve ark., 2006, Kolaylı ve ark., 2008).

$\mathrm{Bu}$ çalışmanın amacı Doğu Karadeniz bölgesinde yaygın olarak yetişen ve meyveleri sıkça tüketilen taflan veya karayemiş olarak bilinen $P$. laurocerasus bitkisinin yaprak ve çekirdeklerinin ferrotiyosiyanat metodu ile total antioksidan kapasitesini belirlemektir.

\section{Materyal ve Metot}

\subsection{Kullanılan Malzemeler}

P. laurocerasus yaprağı ve meyve çekirdeği, \% 96'llk etil alkolden 781,25 ml alınıp mezüre konuldu ve 1000 ml'ye tamamlanarak \% 75'lik etil alkol hazırlandı. \% 37'lık HCl çözeltisinden $7,949 \mathrm{ml}$ alındı ve 100 ml'ye tamamlanarak \% 3,5' luk stok $\mathrm{HCl}$ çözeltisi hazırlandı. 0,397 gr $\mathrm{FeCl}_{2}$ alınıp \% 3,5'luk HCl ile 100 ml'ye tamamlanarak 0,02 M'l1k FeCl2 stoğu elde edildi. 30 gr amonyum tiyosiyonat alındı ve 100 ml'ye tamamlanarak \% 30'luk amonyum tiyosiyonat stoğu hazırlandı. 45 
$\mathrm{ml}$ tampon çözeltisi, $155 \mu \mathrm{l}$ linoleik asit ve $160 \mathrm{ml}$ tween 20 karıştırılarak linoleik asit emisyon stok çözeltisi hazırlandı.

\section{2. Örnekleme Metodu}

P. laurocerasus Ordu ili Turnasuyu mevkiinden Ağustos 2016 tarihinde toplandı. Toplanan örnekler temizlendikten sonra etüvde kurutuldu ve mekanik öğütücü ile toz haline getirildi.

\subsection{Ekstraktların Hazırlanışı}

Kurutulan ve öğütülen örnekler etanol ve metanol çözücüleri kullanılarak ekstrakt haline getirildi. Etanol ve metanol ekstraksiyonu için 20'şer gram bitki örneği $400 \mathrm{~mL}$ çözücü ile oda koşullarında çalkalamalı su banyosunda 300 rpm'de 3 saat inkübasyona tabi tutuldu (Tawaha, 2007). Süzgeç kâğıdı kullanılarak süzüldü ve süzüntülerin çözücüleri bir süre evaporatörde $40{ }^{\circ} \mathrm{C}$ de uçuruldu. Daha sonra beherlere alınan örnek etüvde $40{ }^{\circ} \mathrm{C}$ 'de kazınacak forma gelene kadar çözücülerin uçması sağlandı. Total antioksidan aktivite ölçümleri yapılacak olan konsantrasyonlar için metanol ekstraktı metanolde, etanol ekstraktı ise etanolde $200 \mu \mathrm{g} / \mathrm{ml}$ olacak şekilde hazırlandı.

\subsection{Ferrik Tiyosiyonat Metodu ile Total Antioksidan Kapasitesi Tayini}

Antioksidan aktivite ferrik tiyosiyanat metodu kullanılarak (Pan ve ark., 2007) belirlenmiştir. Bu metoda göre in vitro koşullarda linoleik asit oksidasyonu oluşturulur ve oksidasyon sırasında Fe2+ iyonları Fe3+ iyonlarına yükseltgenir. Belirli aralıklarla inkübasyondaki karışımdan örnek alınarak spektrofotometrik ölçüm ile peroksitlerin oluşumu takip edilir. Absorbans değerinin yüksek olması peroksit konsantrasyonunun da yüksek olduğunu gösterir.

Belirli konsantrasyondaki örnek ekstraktından $1 \mathrm{ml}$ alınıp üzerine $0,02 \mathrm{M} \mathrm{pH=7}$ olan fosfat tampon çözeltisi, $155 \mu$ l linoleik asit, $160 \mathrm{ml}$ tween 20 karışımından $45 \mathrm{ml}$ eklenerek iyice karıştırıldı. Daha sonra reaksiyon karışımı ağzı kapaklı tüplerde $37{ }^{\circ} \mathrm{C}$ 'de inkübasyona bırakıldı. İnkübasyon sırasında çeşitli zaman aralıklarında $0,1 \mathrm{ml}$ örnek alınarak üzerine 4,7ml \%75 v/v etanol, 0,1ml \%30 v/v amonyum tiyosiyonat ve 0,1 $\mathrm{ml}$ 0,02 M FeCl2 eklendi ve vorteks ile karıştırıldı.

Lipit oksidasyonu sonucu oluşan peroksitler $\mathrm{Fe}+2$ iyonlarını $\mathrm{Fe}+3$ 'e yükseltger ve oluşan $\mathrm{Fe}+3$ tiyosiyonat ile reaksiyona girerek $500 \mathrm{~nm}$ 'de maksimum absorbansa sahip bir kompleks oluşturur. Aynı koşullar antioksidan madde içermeyen kontrol örneği için de uygulanmıştır. Yapılan tüm deneyler üç tekrarlı olarak gerçekleştirilmiş olup ortalamaları alınmıştır.

Lipit peroksidasyonu inhibisyonu hesaplanması aşağıdaki formül ile yapılmıştır; 
$\%$ LPI $=100-[($ Absörnek /Abskontrol $) \times 100$

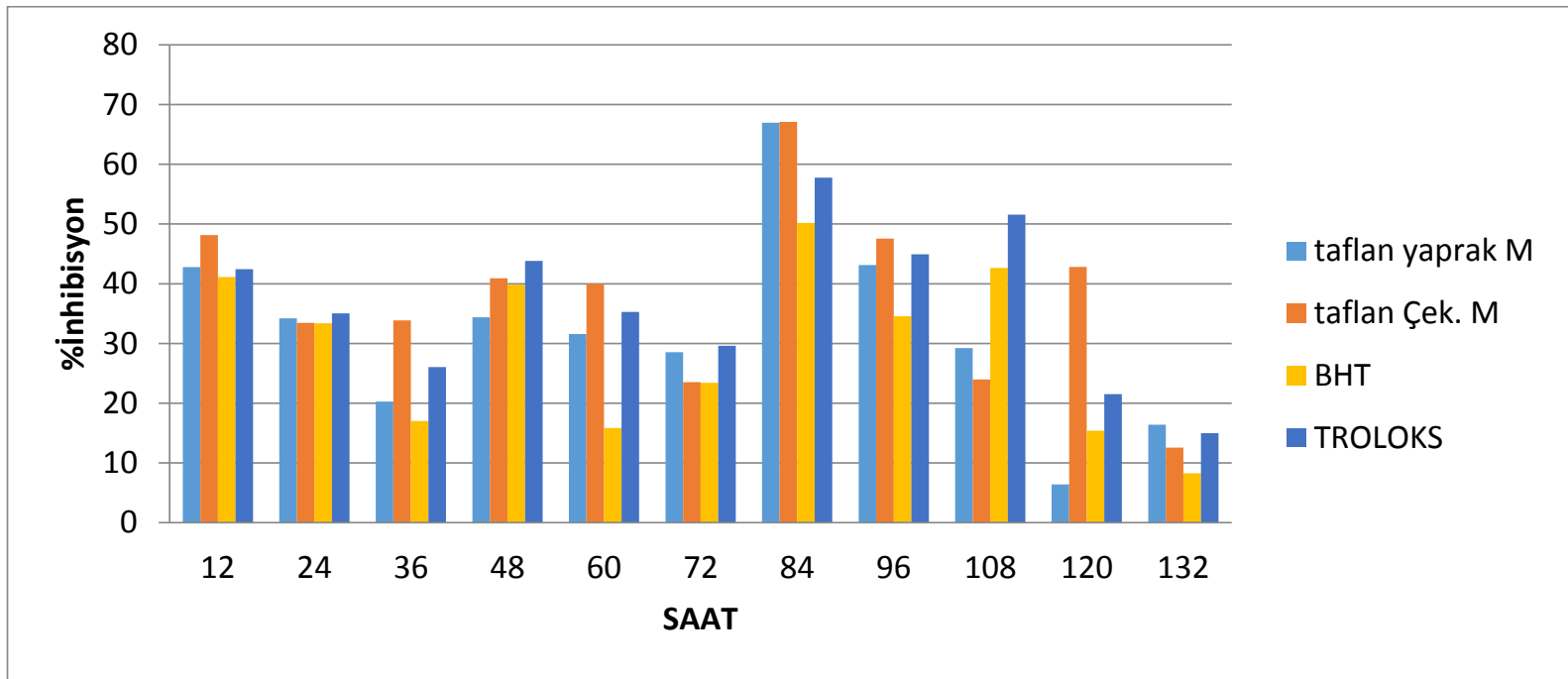

Şekil 1. Taflan yaprak ve çekirdeğinin metanol ekstraktlarının yüzde inhibisyon değerlerinin BHT ve troloks ile karşılaştırılması

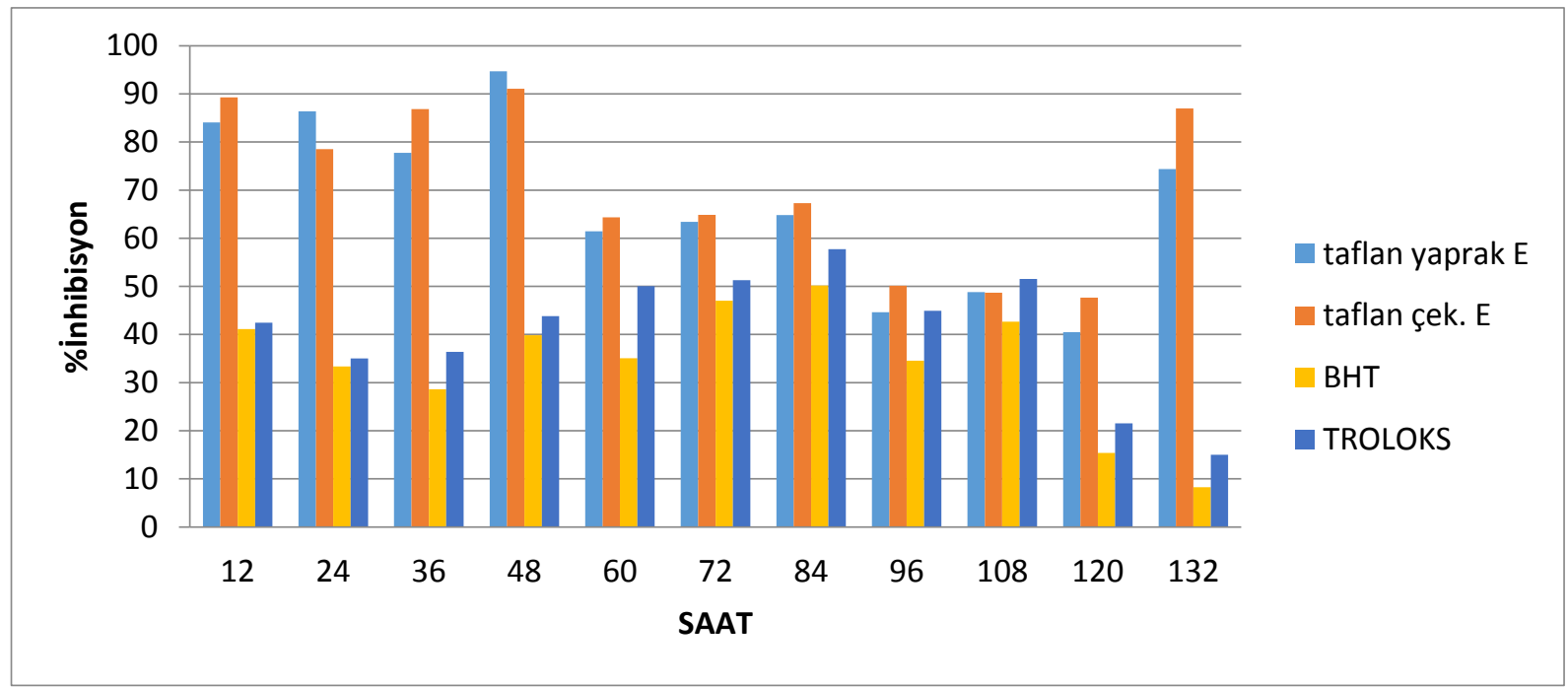

Şekil 2. Taflan yaprak ve çekirdeğinin etanol ekstraktlarının yüzde inhibisyon değerlerinin BHT ve troloks ile karşılaştırılması

\section{Bulgular ve Tartışma}

Çoğu hastalığın patogenezinde önemli bir faktör olan serbest radikaller antioksidan mekanizmalar tarafından bertaraf edilebilmektedir. P. laurocerasus taflan ya da karayemiş olarak bilinen, ülkemizde özellikle Doğu Karadeniz bölgesinde yetişen ve meyvesi sıkça tüketilen bir bitkidir. Meyvesinde bulunan doğal flavanoidler, vitamin ve mineraller ile P. laurocerasus zengin bir besin kaynağının olması yanı sıra farmasötik açıdan da kıymetlidir.

Taflan bitkisinin mikrodalga, ultrason ve sokholet ekstraksiyonu gibi farklı ekstraksiyon teknikleri denenmiş olan bir çalışmada en verimli ekstraksiyonun sokholet ekstraksiyonu olduğu, 
antioksidan ve fenolik içerik bakımından ise mikrodalga ekstraksiyonunun daha verimli olduğu belirtilmiştir (Karabegović ve ark., 2014). P. laurocerasus bitkisinin tip II diabete karşı etkinliği ile ilgili yapılan bir araştırmada, alloksan ile diabet yapılmış sıçanlara bitki ekstraktları verilmiş ve kan şekeri seviyeleri incelenmiştir. Taflan ekstresinin 500 ve $1000 \mathrm{mg} / \mathrm{kg}$ dozlarda kan şekerini anlamlı olarak düşürdüğü kaydedilmiştir. Dahası glikazid ile oluşturulan hipoglisemiyi ve tokluk kan şekerini normal seviyeye getirdiği belirtilmiştir (Türkoglu, 2013). Sahan'ın yaptığı invitro bir çalışmada $P$. laurocerasus bitkisinin etanol ve su ekstraklarının antifungal etki gösterdiği belirtilmiştir (Sahan, 2011). Demir ve arkadaşlarının başka bir in vitro araştırmasında, taflan bitkisinin insan kanser hücrelerine karşı sitotoksik etkisi incelenmiş, akciğer, kolon, karaciğer ve serviks kanseri hücre hatlarında selektif olarak sitotoksik etki gösterdiği saptanmıştır. Kolon kanseri hücrelerinde en yüksek sitotoksik aktivite bulunmuştır ve IC50 değeri $265.2 \mu \mathrm{g} / 1$ olarak kaydedilmiştir (Demir ve ark., 2017).

Yapılan bu çalışmanın sonuçlarına göre, taflan yaprak ve çekirdeğinin metanol ekstraktının yüzde inhibisyon değeri 12. saatte sırasıyla 42,78 ve 48,13 iken, standart antioksidanlardan BHT ve troloksun yüzde inhibisyon değerleri ise 12 . saatte 41,12 ve 42,43 olarak hesaplanmıştır. 36 . saatte ise taflan yaprak ve çekirdeğinin metanol ekstraktı 20,28 ve 33,88 yüzde inhibisyon değerine sahip iken, BHT ve troloks 48. saatte sırasıyla 17,02 ve 26,06' dır. Taflan yaprak ve çekirdeğinin metanol ekstraktlarının yüzde inhibisyon değeri 84. saatte maksimum değere ulaşarak sırasıyla 66,97 ve 67,10 olarak hesaplanmıştır. Buna karşın BHT ve troloksun yüzde inhibisyon değerleri ise 50,18 ve 57,75 olarak bulunmuştur (Şekil 1).

Taflan yaprak ve çekirdeğinin etanol ekstraktlarının yüzde inhibisyon değerleri ise sırasıyla 12. saatte 84,06 ve 89,27 iken, 36. saatte 77,76 ve 86,84 olarak hesaplanmıştır. Taflan yaprak ve çekirdeklerinin etanol ekstraktları ise en çok 48. saatte yüzde inhibisyon göstererek 94,67 ve 91,06 değerlerine ulaşmışlardır. BHT ve troloksun yüzde inhibisyon değerleri 48. saatte ise sırasıyla 39,85 ve 43,81 olarak hesaplanmıştır (Şekil 2).

\section{Sonuçlar ve Öneriler}

Sonuç olarak yöresel ismi taflan veya karayemiş olan $P$. laurocerasus bitkisinin yaprak ve çekirdeklerinin etanol ve metanol ekstraktları elde edilmiş ve total antioksidan kapasiteleri ferrotiyosiyanat metoduna göre saatlere bağlı olarak ölçülmüştür. Taflan bitkisinin yaprak ve çekirdeğinin standart antioksidanlar olarak bilinen BHT ve trolokstan daha yüksek antioksidan kapasiteye sahip oldukları tespit edilmiştir. Etanol ekstraktları daha yüksek antioksidan kapasite göstermiştir. İlaveten, taflanın çekirdeğinin yaprağına göre daha fazla antioksidan kapasiteye sahip 
olduğu söylenebilir. Doğu Karadeniz bölgesinde yoğun olarak bulunan ve sıkça tüketilen taflan bitkisi üzerine daha detaylı analizlerin yapılması gerekmektedir.

\section{Kaynaklar}

Alasalvar, C., Al-Farsi, M., Shahidi, F., (2005). Compositional characteristics and antioxidant components of cherry laurel varieties and pekmez. J. Food Sci. 70 (1), 47-52.

Ayaz, F.A., (2001). Changes in phenolic acids of cherry laurel (Laurocerasus officinalis 'Oxygemmis') fruit during maturation. Acta Biol. Cracov. Bot. 43, 23-26.

Colak, A., Özen, A., Dincer, B., Güner, S., Ayaz, F.A., (2005). Diphenolases from two cultivars of cherry laurel (Laurocerasus officinalis Roem.) fruits at an early stage of maturation. Food Chem. 90 (4), 801807.

Demir, S., Turan, I., Demir, F., Ayazoglu Demir, E., \& Aliyazicioglu, Y. (2017). Cytotoxic Effect of Laurocerasus officinalis Extract on Human Cancer Cell Lines. Marmara Pharmaceutical Journal 21, 121-126.

Erdemoglu, N., Küpeli, E., Yes, İlada, E., (2003). Anti-inflammatory and antinociceptive activity assessment of plants used as remedy in Turkish folk medicine. J. Ethnopharmacol. 89 (1), 123-129.

Gülçin Đ, Berashvili D, Gepdiremen A (2005). Antiradical and antioxidant activity of total anthocyanins from Perilla pankinensis Decne. J. Ethopharmacol. 101, 287-293.

Karabegović, I. T., Stojičević, S. S., Veličković, D. T., Todorović, Z. B., Nikolić, N. Č., \& Lazić, M. L. (2014). The effect of different extraction techniques on the composition and antioxidant activity of cherry laurel (Prunus laurocerasus) leaf and fruit extracts. Industrial Crops and Products, 54, 142-148.

Kolayli, S.,Kücük,M., Duran, C., Candan, F., Dinc, er, B., (2003). Chemical and antioxidant properties of Laurocerasus officinalis Roem. (cherry laurel) fruit grown in the Black Sea region. J. Agric. Food Chem. 51 (25), 7489-7494.

Kolayli S, Aliyazıcıoğlu R, Ulusoy E, Karaoğlu Ş (2008). Antioxidant and antimicrobial activities of selected Turkish honeys. Hacettepe J. Biol. Chem. 36(2), 163-172.

Liyana-Pathirana C. M, Shahidi F, Alasalvar C (2006). Antioxidant activity of cherry laurel fruit (Laurocerasus officinalis Roem.) and its concentrated juice. Food Chem. 99, 121-128.

Pan Y., Zhang X., Wang H., Liang Y., Zhu J., Li H., Zhang Z., Wu Q., (2007). Antioxidant potential of ethanolic extract of Polygonum cuspidatum and application in peanut oil. Food Chem. 105(4), 15181524.

Sahan, Y., (2011). Effect of Prunus laurocerasus L.(cherry laurel)leaf extracts on growth of bread spoilage fungi. Bulg. J. Agric. Sci. 17 (1), 83-92.

Tawaha K., Alalı F. Q., Gharaıbeh M., Mohammad M., El-Elımat T., (2007): “Antioxidant activity and total phenolic of selected Jordanian plant species." Food Chemistry, 104, 1372-1378.

Türkoğlu M, Dündar C, Süleyman H., (2013, 29-31 Mart) Bitkisel İlaç Geliştirme Süreci: Prunus lauracerasus Ekstresinin Tip II Diyabete Karşı Etkinliği. İlaç Kimyasi Üretimi Teknolojisi, Standardizasyonu Kongresi, Kimyagerler Dernegi, Antalya. 